\title{
Classification of plant communities and fuzzy diversity of vegetation systems
}

\author{
E. Feoli \\ Department of Life Sciences, University of Trieste, 34127 Italy
}

Keywords: Eigenanalysis, Evenness, Fuzzy systems, Hierarchy, Pattern, Similarity theory.

Abstract: After stressing the need to keep separated the concept of variability and/or inequality and dissimilarity from that of diversity, it is suggested that diversity of a system should be measured primarily by the number of different classes $(K)$ we can define in it (richness) by classification or identification processes. An index $\delta$, ranging between 0 and 1 , that summarizes the similarity pattern within the system, can be used if necessary to transform $K$ to a "fuzzy" diversity number, according to the idea that the higher is the similarity within the system the lower should be its diversity. Another index, $\rho$, is proposed to measure the "loss" of diversity due to similarity within the system, an index that fits the concept of "redundancy". Since every diversity vector may be interpreted as a crisp symmetric similarity matrix, of which the Gini-Simpson's index is the average dissimilarity, while the index of Shannon is the entropy of its eigenvalues, the index $\delta$ can be chosen to quantify one among the following similarities: a) the overall average similarity of the classes considering the within classes similarity equal to 1 and the between classes similarity equal to 0 (crisp similarity pattern): this is coincident with the evenness of the proportion of importance of the classes, b) the average similarity between the classes without considering evenness, or c) the combination of the two similarities (similarity between the classes and evenness). In these last two cases, the similarity between the classes is characterizing the similarity pattern of a system in a fuzzy way (fuzzy diversity). It is stressed that the diversity of vegetation systems may be of two complementary types: plant individual-based diversity and plant community-based diversity. If we assume that each plant community type corresponds to one habitat then habitat diversity (or niche width) can be calculated for each class of plant individuals according to the number of classes of plant communities in which we can find it. Habitat diversity can be used to measure the indicator value of species or other classes of plant individuals and of plant communities. In this last case, we have to consider the distribution of plant communities in classes defined by environmental factors. It is suggested that the terminology alpha, beta, gamma diversity can be useful only if used to distinguish types of diversity in vegetation systems: alpha diversity = plant individual based diversity, gamma diversity $=$ the union of alpha diversities, beta diversity = plant community based diversity. Thanks to the availability of mathematical tools, it is concluded that rather than being worried about measuring diversity it would be more fruitful to worry about why we are willing to measure it.

For there are never in nature two beings which are exactly alike,

and in which it is not possible to find a difference either internal or based on an intrinsic property.

Still monads need to have some qualities, otherwise they would not even be existences. And if simple substances did not differ at all in their qualities, there would be no means of perceiving any change in things.

G. W. Leibniz. 1714. La Monadologie.

\section{Introduction}

Diversity is an intrinsic property of the Universe (even atoms have their diversity given by protons, neutrons and electrons), a property that we, as living beings, have started to analyze from the beginning of our existence. Diversity can be inspected for any kind of system living or not. The definition and analysis of the systems in terms of components and relationships, are the main aims of all the human cultural activities. Languages, science and mathematics are the results of this analysis and in turn become tools to improve our knowledge and communication about diversity. It is obvious that diversity emerges and is codified by hierarchical classification processes, and that these are always based on the concept of similarity: objects (tangible or not) considered similar enough with respect to some set of characters (one, few or many) belong to the same class, objects considered not enough similar belong to different classes. Classes may be grouped according to hierarchical classifications (see Allen and Starr 1982, for a great discussion on "hierarchy") in function of needs of abstraction (Juhász-Nagy 1993). In short, speaking roughly and considering the ordinary life, for a non-botanist, plants are plants (only one class of living organisms) and for a noneconomist money is money: a non-botanist is interested in the diversity of plants only under special circumstances e.g., when he wants to buy a plant for a gift or when he selects legumes or salads to eat etc.; a common mortal is interested in the diversity of currency only when he is going abroad. With this I mean that the objects can be viewed under different perspectives and classified in different ways according to our needs and circumstances. It follows that we are using the word "diversity" only when we are dealing with a set of tangible or non-tangible objects grouped into different classes. Diversity, variability or inequalities (in the sense of Maignan et al. 2003) and dissimilarity, notwithstanding diversity implies the concepts of variability and dissimilarity, should not 
to be considered synonymous. Variability and dissimilarity are words meaning that there are changes of values of single or set of variables (multi-variables) within a given set of objects, diversity means that in the context of our discourse, there are classes of objects that we consider different, in this sense, variability and dissimilarity may be the causes of diversity "perception". The number $(K)$ of classes of different objects of a system should be its diversity, in line with what is also said by Whittaker (1972) for vegetation systems: "The most generally appropriate measure of diversity is simply $S$, the number of species per unit area as represented in some kind of standard sample" $(S=K)$. However, in the past an accepted technical definition of diversity, whose authorship is not clear for me (maybe Margalef 1958, see Pielou 1975, Magurran 1988), indicated that diversity should be given by the combination of the number of classes and their proportional importance, i.e., richness and evenness. Based on this definition, many formulas have been proposed to combine the two quantities by a single number. The most often used ones are the Shannon index, from information theory (or from the entropy of thermodynamics) and the formula of Gini-Simpson (see Whittaker 1972, Magurran 1988, 2004) generalized by Rényi (1961) and later by Hill (1973) and Patil and Taillie (1976). The definition of diversity evolved further when the idea of considering also the dissimilarity between the classes was introduced (cf. Rao 1982, 2010, Feoli et al. 1992, Ricotta and Szeidl 2006, 2009). This certainly was a consequence of the idea that at parity of the number of classes and evenness of the importance values (see Hill 1973, Ricotta et al. 2001, Ricotta 2003, 2004), the system with a higher similarity between the classes should be less diverse than the one with lower similarity. This idea followed the one of hierarchical diversity proposed and discussed by Pielou (1975) and Feoli and Scimone (1984a) to show, by the hierarchical diversity profiles, how much the diversity would change by grouping the classes in a hierarchical process (see Feoli 2012, Feoli et al. 2013). One definition that keeps into consideration the similarity within the system has been formulated by Feoli et al. (2013) as follows: "Diversity is a property of a sampling unit (a system) containing a set of events or objects $(O)$ of any kind, material or immaterial, real or imaginary, of which $C(O)$ is a partition, measurable by combining the number of classes $(K)$ of $C(O)$ and the average dissimilarity between the $K$ classes". The similarity-dissimilarity may be calculated using different characters, intrinsic and/or extrinsic, chosen to compare the classes and by one of the many resemblance functions ranging between 0 and 1 (Orlóci 1972, 1978, Podani 2000, 2007). The intrinsic characters are those used to define the classes, the extrinsic ones are those that are considered for specific aims and that were not considered to build up the classes. The above definition of diversity does not refer to evenness (equitability between the classes), because we can interpret any diversity vector with $K$ components (classes) as a crisp similarity matrix $Q \times Q$, where $Q$ is the sum of all the units used to measure the importance of the $K$ classes, transformed into an integer number. The matrix $Q \times Q$ is a disjoint matrix with $K$ sub-matrices. Feoli (2012) and Feoli et al. (2013) showed that the index of Simpson is the average similarity of that matrix (the index of Gini-Simpson the average dissimilarity), while the index of Shannon is the entropy of its eigenvalues. This is because each of the disjoint $K$ matrices, that would correspond to the perfect crisp situation, implicit in a diversity vector, has its independent sets of eigenvalues and eigenvectors (Wilkinson 1965, Feoli 1977). Consequently, Feoli (2012) and Feoli et al. (2013) proposed to distinguish between two types of diversity, the "crisp diversity" and the "fuzzy diversity" depending on the way we want to consider the similarity pattern (let us to abbreviate it by $\delta$ ) of the classes of a given system. It is crisp when we assume that the similarity within the classes is equal to 1 and the similarity between the classes is equal to 0 , it is fuzzy when we assume that such similarity may range between 0 and 1 (crisp $\delta \rightarrow$ crisp diversity, fuzzy $\delta \rightarrow$ fuzzy diversity). The similarity between the classes may be interpreted as the degree of belonging of one class to the other class (Zhao 1986). It follows that for calculating the fuzzy diversity we need a matrix of similarity dissimilarity $(S)$ between the classes. This may consider the dissimilarity between all the individuals belonging to different classes or some "summary" vector representing the classes (i.e., centroid, medoid, min. or max. values etc.)

\section{$\mathbf{K}, \delta$ and $\rho$ : richness, similarity and redundancy}

The aim of this paper is to discuss the suggestion of measuring diversity of a system by the simple formula

$D=K \delta$,

$K$ is the number of classes defined by an identification or by a classification process and $\delta$ the index, ranging between 0 and 1 , that summarizes the similarity (dissimilarity) pattern of the classes within the system.

$D$ is equal to $K$ if $\delta=1$ and $D$ is equal to 0 if $\delta=0$. We can calculate $\delta$ in many ways. After we have defined $K$, by identification or classification processes, thanks to the fact that any diversity vector can be interpreted as a similarity crisp matrix $(Q \times Q), \delta$ can be chosen to quantify one among the following similarities within a system: a) the overall average similarity of the classes considering the within similarities equal to 1 and the between similarity equal to zero (crisp diversity): this considers the proportion of importance of the classes; $b$ ) the average similarity between the classes without considering the evenness and finally c) the combination of the two similarities. In these last two cases (b and c) the similarity between the classes is characterizing the similarity pattern of a system in a fuzzy way (fuzzy diversity) (Feoli 2012, Feoli et al. 2013).

It follows that for calculating the crisp diversity, $\delta$ can be chosen equal to the evenness (Ricotta 2003, 2004, Ricotta et al. 2001) of the formulas of Gini-Simpson or Shannon or to the formula proposed by Podani (2006) (similarity of type a). While in case of fuzzy diversity it should be equal to an average dissimilarity between the classes calculated by any dissimilarity function, in case of similarity of type b), and equal to the evenness of the formula of Rao (1982) or Ricotta and Szeidl (2006) in case of similarity of type c). 
In conclusion, $\delta$ is a similarity index that may have one or two components, the "fuzzy" similarity $(S)$ between the classes and the "crisp" similarity between them (evenness, $E$ ). Therefore, formula (1) can be seen with three components $K, S$ and $E$. To express diversity by only $D$ could be not much informative because the same value of diversity can be obtained with different combinations of values of $K, S$ and $E$ : low richness may be compensated by high evenness and low similarity; high richness by low evenness and high similarity etc. The combinations of values of $K, S$ and $E$ may be infinite within what we can consider the basic 8 combinations of maximum and minimu values of $K, S$ and $E$. Therefore, when we want to compare the diversity of different systems by keeping into consideration also their similarity patterns, we should use the three values of $K, S$ and $E$ in a ternary plot such that in Figure 1 or in other techniques of multivariate analysis. To build the ternary plots as in the case of other techniques of multivariate analysis $K, S$ and $E$ should be normalized or standardized to become a-dimensional and comparable. In the example of Figure 1, all the three systems have the same $K$, but its importance is not the same with respect the other components in the context of the comparison.

The recognition that formula (1) could not be completely explanatory about the components of diversity (richness and similarity pattern) does not mean that we have to leave it out the discourse of diversity. Formula (1) is pretty well in line,with the fact that diversity is based on classification and that classification is based on similarity. Its utility becomes relevant if we think that similarity would play a role in defining diversity: "more similarity less diversity", i.e., we have to accept the idea that the diversity of a system could be less than that of another one even if its richness would be higher.

An alternative to formula (1) could be $D=K^{\delta}$, proposed by Feoli (2010) to measure the habitat diversity of heath lands of Italy. In this case, $D$ is equal to 1 when $\delta=0$ and it would be $K$ if $\delta=1 . D=K^{\delta}$ corresponds to the N1 of Hill (1973) if $\delta$ is equal to the evenness of the Shannon's entropy. I con-

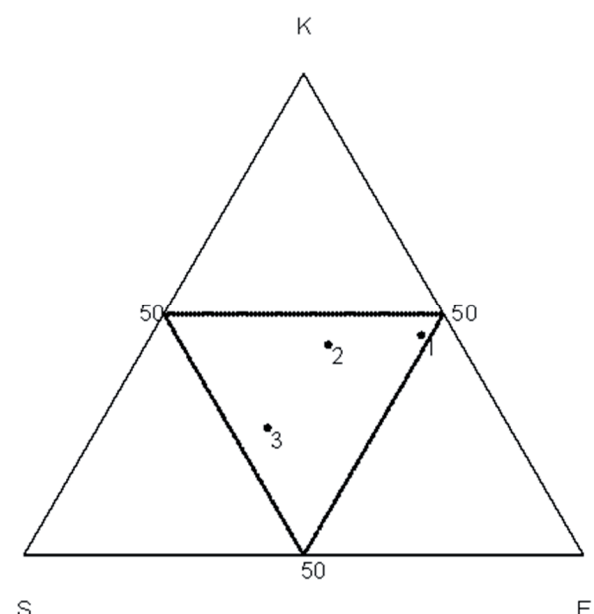

Figure 1. Ternary plot showing the position of three system described by $K, S$ and $E$ as follows: 1) $K=2, S=0.05, E=0.92$; 2) $K=2, S=0.2, E=0.65$; 3) $K=2, S=0.60 E=1 . K, S, E$ have been normalized before making the plot. sider here only formula (1) because the second one shows very small differences for very different $K$, for example for $K$ $=200$ and $\delta=0.2, D$ is equal to 2.88 , for $K=100$ and $\delta=0.2$, $D$ is equal to 2.52 , while with formula (1) $D=40$ for $\mathrm{K}=200$, and it is 20 for $K=100$, i.e., just the half (linear relationship!). I do not know if such very simple formula has been proposed in a such a simple and immediate way, perhaps yes. It was actually used by Jost (2010) while discussing the relationships between evenness and diversity, but not proposed as a measure of diversity. I was not able to find the explicit references, supporting it, for sure a similar one was proposed by Feoli et al. (1992), to measure what they call landscape biotic diversity: $D B T=n D T$, where $\mathrm{n}$ is the average number of species per square meter and $D T$ is the entropy of the land cover of vegetation types multiplied by their average dissimilarity in terms of species. However, in formula (1) $\delta$, that would correspond to $D T$, ranges between 0 and 1 and may be calculated as the evenness of the $K$ classes or as their average dissimilarity or as the combination of both (evenness and similarity), depending on what we want to achieve by the formula.

Although formula (1) ranges between 0 and $K$, or 1 and $K$, depending on $\delta$, it does not give the diversity numbers, effective numbers or equivalent numbers of Hill (1973) (see Jost 2007, Pavoine et al. 2016 and references therein), because $D=K \delta$ is not meant to be the number of equally important classes that gives a definite diversity index (e.g., Shannon or Gini Simpson) as in the case of equivalent numbers of Hill (1973). In formula (1) $\delta$ is just a "weight", explicitly formulated in the context in which we are measuring diversity. It is to stress that for any $D$, obtained by any formula of diversity proposed in literature, there exists a $\delta$ or, in other words, we can calculate one $\delta$ :

$\delta=D / K$

which leads to

$K=D / \delta$

If we pass to logarithms

$\ln K=\ln D-\ln \delta$.

That is,

$\ln D=\ln K+\ln \delta$.

Formula (4) would support the idea of Jost (2010) that richness can be "decomposed" into two "independent" components: diversity and an "inequality factor" that, in the case dealt by Jost (2010) is the reciprocal of evenness $(1 / \delta)$. On the other side, formula (5) would support the idea that any $D$ can be "decomposed" in $K$ and $\delta$, that however by definition cannot be independent as stressed also by Jost (2010). It is obvious that $K$ remains $K$, the number of defined classes, and that the only factor that should be calculated is $\delta$, as it is obvious that the evenness of any diversity vector with $K$ components may depend on $K$ irrespective the formula we use to calculate it (e.g., Gini-Simpson or Shannon, see Pielou 1975, Magurran 1988, Feoli et al. 2013). For example, given a certain $Q$ (the total of the importance of the classes in a diversity vector) the maximal evenness is always equal to 1 irrespective of $K$, but the "actual" evenness is depending on $K$. For example, if we consider two diversity vectors with $Q$ 
$=36$, one with 6 classes $X_{1}=(31,1,1,1,1,1)$ and the second with 4 classes $X_{2}=(33,1,1,1)$, both showing the minimal possible evenness for integer values, the evenness according to Shannon and Gini-Simpson is respectively 0.35 and 0.31 for the first vector and 0.27 and 0.21 for the second. If we consider a situation of different $Q$, but of equal ratio between the value of dominance and the other values as in the following case: $X_{3}=(4,1,1,1,1,1)$ and $X_{4}=(3,0.75 .0 .75,0.75)$, again the evenness of the vector with $K=6$ is higher than the evenness of the vector with $K=4$ (respectively 0.87 for Shannon and 0.90 for Gini-Simpson and 0.84 for Shannon and 0.81 for Gini-Simpson).

The effects of $\delta$ on $K$ can be indicated as the reduction of richness due to similarity and can be interpreted as a redundancy ( $\rho$ ) (Pielou 1975, Feoli et al. 1984, Ricotta et al. 2018) of the systems in terms of the characters used to evaluate the similarity. It can be measured in relative terms by the ratio:

$\rho=(K-K \delta) / K$

The reduction of diversity $\left(\rho_{\phi}\right)$ due to a fuzzy $D_{\phi}$ with respect to a crisp diversity $D_{\chi}$ can be measured in an analogous way as:

$\rho_{\phi}=\left(D_{\phi}-D_{\chi}\right) / D_{\phi}$

In the case of $\mathrm{X}_{1}, \rho=(K-K \delta) / K=(6-2.1) / 6=0.65$ and $(6-1.86) / 6=0.69$, in the case of $\mathrm{X}_{2} \rho=(4-1.08) / 4=0.73$ and $(4-0.84) / 4=0.79$. We can say that at parity of $Q$ and with more or less the same pattern of dominance the loss is higher when $K$ is lower.

After discussing on alpha and beta diversity of Whittaker $(1960,1972)$, I will show how many diversities of vegetation systems we can calculate by formula (1) or by any other formula that is able to keep into consideration the similarity between the $K$ classes) and with examples based on very simple artificial data, I will show the effects of $\delta$ on $K$ using $\rho$.

\section{The plant community concept and its role in studying fuzzy diversity of vegetation systems}

Vegetation is a system built up by individual plants that are interacting between themselves and the environment for what Darwin (1859) calls the "struggle for life". The vegetation systems may be individuated at different hierarchical conceptual levels and geographical scales, from that of few plants living on a clod of earth to the vegetation of the whole biosphere and they can be studied under different perspectives and with different aims (Mueller-Dombois and Ellenberg 1974, Wildi 2017). The scale and grain are very important issues in studying the vegetation systems in all their aspects and the concept of plant community would play a fundamental role to avoid useless work. I think that if we want to study vegetation by a scientific point of view, we should get data that can be analyzed by mathematical methods within a logical framework that would overcome the problems related to the infinite possibilities to select a grain to be used for the analysis. The concept of plant community, as accepted by the international congress of botany in 1910 and by the Braun Blanquet's approach (van der Maarel 1975), is offering such operative logical framework (see Biondi et al. 2004, Orlóci 2015a) because it conditions all the sampling units to represent an "homogeneous" entity of the "same ecological meaning", that is the plant community. It follows that the acceptance of the concept of plant community leads to an automatic definition of the spatial grain (of not fixed size) used to study the vegetation systems of any area. This is the strength of the concept that, if viewed as an operative one (e.g., Wilson and Chiarucci 2000 , Biondi et al. 2004, Orlóci 2015a), overcomes its weakness. Among these the major ones are related to the fact that plant communities have not boundaries and often cannot be sampled in their completeness regarding the species that may live on them, because the area of sampling could be too small or too fragmented, and the fact that the judgement of environmental homogeneity is always subjective. Within a plant community there are several patches of plants of the same species that create evident heterogeneity, and it is almost impossible to collect chemical physical data in all the patches to see if the samples are belonging to the same multivariate unimodal distribution. Obviously, the plant community is not an organism, a discrete entity, however it can be perceived in nature as a unit that can belong to a set of similar plant communities (vegetation types) and that can be interpreted as a "working mechanism" that can be defined by a certain number of species with a peculiar pattern of their abundance ("The plant community may be described from two points of view, for diagnosis and classification, and as a working mechanism" Watt 1947, Newman 1982, van der Maarel 1996). The fact that it is a working mechanism with a given floristic composition and quantitative structure, could be directly supported by the point of view "for diagnosis and classification". It is evident that for each plant community type we can find an area that contain almost all the species living in it (the minimal area, or the biological minimal area, see van der Maarel 2005 for a discussion on the concept), and also there are many evidences that to "definite" species combinations there are corresponding, in a statistical significant way, "definite" quantitative patterns between the species (Avena et al. 1981 and more recently Wilson 2012) and further, there is not a mystery that vegetation types based on plant community concept are strictly related to environmental classes (e.g., Ferrari et al. 1983, Feoli 1983, Feoli and Ganis, 1985, Feoli and Orlóci 2011). These facts would certainly support the idea that the importance values of the species are defined by the functional needs of the system. This would open a very interesting broad discussion about "system theory" (see Von Bertalanffy 1968) that is out of the scope of this paper. However, this would suggest that, in the study of vegetation diversity, the quantitative pattern of the importance between the $K$ classes should be considered only in some determinate circumstances, e.g., when we are interested to study the relationships between the changes of importance of the classes of the system and the changes of their class composition (e.g., in experiments of fertilization see Kizekova et al. 2017, or along gradiets, Whittaker 1960, 1972).

The discussion about the existence of plant community carried out by Wilson (1991,1994), Keddy (1993) and Palmer and White (1994), Dale (1994) and Wilson et al. (1995) can be 
considered over by the paper of Wilson and Chiarucci (2000) suggesting that plant community even if it does not exist as a discrete entity is a convenient unit to study vegetation. Biondi et al. (2004) suggest that the operative value of plant community overcomes all the weakness of the concept that can be easily compensate by the use of approximate reasoning and fuzzy set theory and methods dealing with uncertainty instead of the traditional probabilistic statistical approaches (Zadeh, 1965, 1978, Feoli and Zuccarello 1986, Roberts 1986, Pillar and Orlóci 1996, Zimmerman 1996, Ricotta and Anand 2006, Orlóci 2015a).

\section{$\beta$ vegetation diversity and plant community classification}

According to Feoli (2012), the diversity of vegetation systems may be defined by two complementary ways: one is based on classes of plant individuals (plant individual based diversity) and the other is based on classes of plant communities (plant community based diversity). In the first case, given a vegetation system, we want to find how many classes of plant individuals are there and what are the relationships between them in terms of importance (proportions) and or/ in terms of similarity or in terms of the combination of the two statistics, and what are the relationships of these classes with the environment. The classes may correspond to species, or other taxonomic groups, functional traits, evolutive traits, chemical, structural etc. (see Feoli 1984ab, Feoli and Scimone 1984b, Orlóci and Orlóci 1985, Orlóci et al. 1986, Feoli and Orlóci 1991, Pillar and Orlóci 1993, 2004, BottaDukàt 2005, Mason et al. 2005, de Bello et al. 2007, Pillar et al. 2009, Ricotta et al. 2015, 2017, 2018, Pavoine et al. 2016, Duarte et al. 2016 and references therein).

In the second case we want to find how many classes of plant communities are there and what are the relationships between them, in terms of plant individual based diversity and in terms of environmental heterogeneity. This, beside having theoretical importance, is very useful for mapping vegetation types and for planning purposes.

The plant-individual based diversity of a vegetation system that covers a given area, may be found by considering or not the plant community concept. If this concept is not considered we are working under a prevailing biogeographical perspective, and I refer to Hui (2008) and Hui and McGeoch (2008) and Chiarucci et al. (2008, 2012), and reference therein, for a discussion on the problems and solutions related to this approach. In this paper I consider useful to measure the diversity of vegetation system by the use of the concept of plant community and I support the idea that by sampling and classifying plant communities (Braun Blanquet 1964, DeCaceres et al. 2015) we can get, within the same effort of data collection, plant-individual based diversity and plantcommunity based diversity of vegetation systems.

Whittaker $(1960,1972)$, anticipated this view, but he did not include the classification of plant communities in his proposal of beta $(\beta)$ diversity. Given a matrix $\mathbf{X}$ of $M$ rows (the classes of plant individuals that in case of Whittaker are spe- cies) and $N$ columns representing stands of plant communities (relevés), the Whittaker's alpha and gamma diversity are respectively the number of species per plant community, and the total number of species in the matrix. I report here some statements of Whittaker's paper from 1972:

"For the measurement of alpha $(\alpha)$ diversity relations I suggest, first, use of a direct diversity expression, $K$ ( $S$ in the original sentence), as a basic measurement whenever possible, second, accompaniment of this by a suitable slope expression when the data permit."

"Beta ( $\beta$ ) diversities, in contrast, are of different dimensional character; they are based on ratios or differences. For different research purposes such ratios or differences are to be measured either along particular coenoclines, or for sets of samples differing from one another along several axes of habitat or community hyperspace. A number of approaches are, however, possible (Whittaker 1960)."

Notwithstanding, according to Whittaker (1972), other approaches are admitted, the $\beta$ diversity is fundamentally the ratio between gamma $(\gamma)$ diversity and the number of species per relevé ("individual beta diversity") or the average number of species of the $N$ relevés (beta diversity of $N$ plant communities). The individual $\beta$ diversity would range between 1 and $M$ ( 1 in case the stand has all the $M$ species, $M$ in case the stand has only one species). The "average" $\beta$ diversity, what is called beta diversity, ranges between 1 and $N$ ( 1 in case the average species number is equal to $M, N$ when there are no species in common between the plant communities, i.e., all the relevés are completely different). According to Feoli (2012), the alpha and gamma diversity of Whittaker would belong to the plant-individual based diversity. Beta diversity would belong to the plant-community based diversity, but only if the columns of the matrix $\mathbf{X}$ would represent vegetation types, i.e., classes of plant communities. The vegetation types may be chosen at different hierarchical levels of syntaxonomy (Braun-Blanquet 1964, van der Maarel 1975). If the columns of $\mathbf{X}$ are just samples of plant communities, the beta diversity of Whittaker should be considered only a measure of average dissimilarity, because without the existence of classes considered different the concept of diversity would collapse (Feoli et al. 1988). Beta diversity can be relativized to 1 by the formula $(\gamma-\alpha) / \gamma$, and it could be used as a $\delta$ for a fuzzy diversity.

However, in the literature the arguments of Feoli et al. (1988) have not been taken seriously into consideration and the vegetation scientists (and others) started to call beta diversity any similarity-dissimilarity measure calculated between any type of objects (e.g., Anderson et al. 2011). In this way also the alpha diversity of Whittaker, when we keep into consideration the fact that a diversity vector may be interpreted as a similarity matrix (crisp or fuzzy diversity), becomes paradoxically a "beta diversity". Recently it was even proposed another type of "beta" diversity that was called zeta diversity $(Z)$. It is the number of species shared by multiple assemblages (Hui and McGeoch 2014). In terms of set theory, this is the intersection between sets. It can be made relative by dividing its value by the total species number in a matrix 
(i.e., the $\gamma$ diversity) as in the case of the index of Jaccard (see Podani and Schmera 2011 for the relationships between the index of Jaccard and the beta and gamma diversity of Whittaker). As such, $Z$ diversity, is even more explicitly than the beta of Whittaker, a measure of similarity. In any case the beta diversity of Whittaker and the zeta diversity of Hui and McGeoch (2014) may be used to calculate the corresponding $\delta$ according to formula 2 ) if $N$ is the number of the $K$ classes considered different plant communities i.e., different vegetation types:

\section{$\delta=\beta / K$ or $\delta=Z / K$}

Accordingly, $\delta$ is equal to $1 / K$ if $\beta$ (or $Z$ ) is equal to 1 (i.e., alpha diversity $=$ gamma diversity), and it is equal to 1 if $\beta$ (or $Z$ ) is equal to $K$. It follows that if $N$ of the matrix $\mathbf{X}$ would represent $K$ classes of plant communities, then $\beta$ (or $Z$ ) becomes a "correct" measure of the fuzzy plant-community based diversity $(D)$ of a vegetation system $(D=\beta$ or $D=Z)$. They are fuzzy measure because they keep into consideration, notwithstanding indirectly, the similarity between relevés. With them we can calculate $\rho$ as in formulae (6) and (7).

The $\delta$ calculated by $\beta / K$ or $\beta / N$ can be used as a measure of dissimilarity of sets of plant communities ranging between 0 (of course it never will be zero) and 1. Other measures of similarities within sets of objects (plots or relevés) are presented by Ricotta and Marignani (2007), Ricotta and Pavoine (2015) and Schmera and Podani (2018 and references therein).

It is worth to stress that when the alpha diversities of the sub-matrices is the same, or when the disjoint sub-matrices have only 1 column vector (situations that are rarely met in vegetation systems), the beta diversity of Whittaker would be equal to the number of completely disjoint sub-matrices of $\mathbf{X}$. It follows that we can say that $\beta$ is approximating in a fuzzy way the number of "potential" completely dissimilar vegetation types in the matrix $\mathbf{X}$. If we consider only two stands $(j, k)$, the argument will become clear. The formula of beta diversity can be written, in terms of the symbolism of the two way contingency table as: $\beta_{j, k}=2(a+b+c) /(2 a+b+c)$, where $a$ is the number of species in common between $j$ and $k$ and $\mathrm{b}$ and $\mathrm{c}$ are the species peculiar of each stand. It follows that in this case $\beta$ may be considered a pairwise dissimilarity measure for binary data ranging between 1 and 2 . The decimal number in between 1 and 2 would be considered a fuzzy estimator (a degree of belonging) of how much the two stands would belong to two different sets. In case of $N$ stands, the number of the decimals after the integer of the number expressing the beta diversity (n), would indicate how much the number of potential different vegetation types would be close to $n+1$.

In conclusion, if we want to be consistent with the meaning of diversity and we want to calculate the so called beta diversity, i.e., the plant community based diversity, we have to classify the plant communities, by finding an optimal number of vegetation types $K$ on the basis of class separation (Feoli and Orlóci 1979, Feoli and Lausi 1980, Dale 1988, Burba et al. 1992, Pillar and Orlóci 1996, Pillar 1999, Tichy 2002, Tichy and Holt 2006, Feoli et al. 2006, 2009, Tichy et al. 2010). Having obtained the classes, we can calculate the fuzzy diversity directly by the beta diversity of Whittaker(1972) or the $Z$ diversity of Hui and McGeoch (2014) or we can use formula (1). In this case $\delta$ can be the evenness of the eigenvalues of the matrix of similarity between the $K$ clusters, weighted or not by the vector of proportion between the $K$ vegetation types (in the system), or by the evenness of the eigenvalues of the similarity matrix between all the stands, this because, thanks to some matrix algebra theorems (Wilkinson 1965), there is a strong correlation between fuzzy sets obtained by cluster analysis and the eigenvectors of the similarity matrix used to obtain the clusters (Feoli 2012, Feoli and Zuccarello 2013). If we want to calculate the crisp plant community based diversity then we do need to calculate the dissimilarity between the $K$ classes, but we can use as $\delta$ any evenness measure related to their importance values (Hill 1973, Pielou 1975, Ricotta 2003, 2004). We can conclude that if $N$ of a matrix $\mathbf{X}$ is a number of vegetation types (classes of plant communities), from the computational point of view, beta diversity and alpha diversity (as well gamma diversity) are the same and the problems to interpret beta diversity as a real diversity are over (see Tuomisto 2010a,b, 2011, Gorelick 2011, Jurasinski and Koch 2011, Moreno and Rodriguez 2011, Ricotta 2017, for further discussions about the terminology concerning species diversity).

In any case I think very useful if, when we are studying a vegetation system of a given area, we would provide the three Whittaker's diversities $\alpha, \gamma, \beta$. For example, if we consider the Coquihalla data used by Feoli and Orlóci (1979) we can say that for all the table (matrix $\mathbf{X}$ ) the average $\alpha$ diversity is 21 , the $\gamma$ diversity is 73 and the $\beta$ "diversity" $(\gamma / \alpha)$ of Whittaker is 3.48. This number is quite close to the number of clusters obtained by cluster analysis (three clusters) and sharply significant according both the chi-squared metrics (Feoli and Orlóci 1979) and the method of Burba et al. (1992) and Feoli et al. (2009) of the evenness of the eigenvalues (based on species similarity and tested by a permutation technique, e.g., Biondini et al. 1991, Pillar and Orlóci 1996, Pesarin 2001). If we calculate the beta diversity of Whittaker (1972) considering the 3 vegetation types and using their gamma diversity as alpha diversity, the beta diversity would be $73 / 47=1.55$ (being 47 the average alpha diversity of the three vegetation types). If we calculate the beta diversity according to formula 1) i.e., $D=K \delta$ where $K=3$ (the number of vegetation types) and $\delta$ is the evenness of the eigenvalues of the similarity matrix between the 45 relevés (calculated by cosine applied to binary data) that is 0.5154 , the beta diversity is $3 \times 0.5154=$ 1.546 , if $\delta$ is calculated as the evenness of the eigenvalues of the similarity matrix between the three clusters that is 0.61 , then the beta diversity is $3 \times 0.61$ i.e., 1.83 . The beta diversity is less than 3 because there is a certain redundancy, i.e., similarity between the types. If we apply the formula 6 ) using this last value, then $\rho=(3-1.83) / 3=0.39$.

\section{How many diversities of vegetation systems?}

The similarity matrices $\mathbf{S}$ between the classes of plantindividuals or plant community (vegetation types) may be calculated in many ways to be used to compute the fuzzy diversity by formulas of Rao (1982), Feoli et al. (1992), Ricotta and Szeidl (2006) or the one of Leinster and Cobbold (2012). 
A discussion of what are the most suitable dissimilarity functions to use in the Rao's formula is given by Pavoine et al. (2005). They may be matrices of similarity based on intrinsic or extrinsic characters or matrices representing topological distances in phylogenetic trees (Podani 2007, Pavoine 2016). Ways to codify hierarchical relationships between species have been presented also by Feoli (1984a), Dale et al. (1989), Feoli and Orlóci (1991), Pavoine et al. (2009, 2016). If the matrix $\mathbf{X}$ represents plant communities described by classes of plant individuals the diversity calculated for the columns are interpretable as niche diversity offered by the stands in which the plant communities have been found. If the matrix $\mathbf{X}$ represents vegetation types described by classes of plant individuals the diversity of vegetation types may be interpreted as the diversity of niches offered by the habitat of vegetation types to the classes of plant individuals (see Whittaker 1972 for a more deep discussion and for fundamental references on niche diversity relationships). The diversity calculated for the classes of plant individuals in matrices of vegetation types represents the habitat diversity of the classes of plant individuals since, thanks to similarity theory (Feoli and Orlóci 2011, Wildi 2017), each vegetation type would represent or correspond to one habitat ( a set of sites with similar environmental characteristics). If the diversity is calculated using matrices in which vegetation types are described by the proportions they have in classes of environmental factors the diversity calculated for each vegetation type would represent the amplitude of its "community niche" (Feoli et al. 1988, Feoli 2010).

Given a matrix $\mathbf{X}$ for classes of plant individuals describing vegetation types we can calculate in total at least 16 diversity types of plant individual based diversity, 8 for the $M$ rows and 8 for the $N$ columns. With the same matrix, if we have a vector of proportion between the vegetation types, we can calculate 8 types of plant communities based diversity. If for example we have a class of plant individuals distributed in the vegetation types we can consider the similarity we have between these vegetation types and the similarity the class of plant individuals has with all the other classes of plant individuals in terms of their distribution in the vegetation types. In the first case we can have a measure of the diversity of the environment in which the class is living, in the second case a measure of its peculiarity with respect the other classes. The number of diversity types can be even higher if we consider sub-matrices given or by subsets of plant individual classes or plant community classes etc. (e.g., Feoli and Lagonegro 1982, suggest to calculate diversity by using "nuclear" and "orbital" species in order to consider the diversity based on discriminant species), and becomes even more high if we decide also to distinguish the many ways to calculate the similarity and the many possible choice of the characters by which measuring similarity.

Table 1 presents the main types of diversity we can calculate on the basis of classes of plant individuals and classes of plant community, with formula 1), however I want to stress that other formulas could be used. It should be clear that the fuzzy diversity, in case of plant individual based diversity can be calculated both by using the similarity between classes of plant individuals (species or plant traits) and also the simi-
Table 1. Types of vegetation diversity $(\mathrm{PIBD}=$ plant individual based diversity; $\mathrm{PCBD}=$ plant community based diversity) that can be calculated by formula 1 ): $\mathrm{K}=$ number of classes, $\mathrm{c}=$ crisp, $\mathrm{f}=$ fuzzy, $\mathrm{i}=$ intrinsic characters, $\mathrm{e}=$ extrinsic characters, $\mathrm{E}=$ evenness of proportions included in $\delta$ (see the text). $\delta$ can be calculated by keeping into consideration the similarity between the stands or vegetation types and the similarity between the classes of plant individuals. So the number of formulas of PIBD with $\delta$ has to be multiplied by 2 (i.e. $M$ or $N$, in analogy to R or Q mode).

$\operatorname{PIBD}(M, N) \mathrm{K}$ K $\delta \mathrm{c}$ K $\delta$ fi $\mathrm{K}(\mathrm{E}) \delta$ fi $\mathrm{K} \delta$ fe $\mathrm{K}(\mathrm{E}) \delta$ fe $\mathrm{K} \delta$ fife $\mathrm{K}(\mathrm{E}) \delta$ fife $\operatorname{PCBD}(N) \quad \mathrm{K}$ K $\delta \mathrm{c}$ K $\delta$ fi $\mathrm{K}(\mathrm{E}) \delta$ fi $\mathrm{K} \delta$ fe $\mathrm{K}(\mathrm{E}) \delta$ fe $\mathrm{K} \delta$ fife $\mathrm{K}(\mathrm{E}) \delta$ fife

Table 2. Four crisp similarity matrices corresponding to a set of 6 units $(Q)$ belonging to two classes in three different ways (B1, $\mathrm{B} 2, \mathrm{~B} 3))$.

\begin{tabular}{cccc}
\hline B1 & B2 & B3 \\
111000 & 111100 & 111110 \\
111000 & 111100 & 111110 \\
111000 & 111100 & 111110 \\
000111 & 111100 & 11110 \\
000111 & 000011 & 111110 \\
000111 & 000011 & 000001 \\
\hline
\end{tabular}

Table 3. Similarity matrices corresponding to 3 diversity vectors in which there are 3 levels of between classes similarity (i.e. there are three similarity matrices for each diversity vectors corresponding to matrices B1, B2, B3 in Table 1, that I call X(3,3), $\mathrm{X}(4,2)$ and $\mathrm{X}(5,1))$

\begin{tabular}{|c|c|c|c|c|}
\hline $\begin{array}{lll}\text { B1 } & 0.5\end{array}$ & 0.5 & B2 0.670 .33 & B3 0.83 & 0.27 \\
\hline 1 & 0.05 & 0.05 & 1 & 0.05 \\
\hline 0.0 & & 0.051 & 0.05 & \\
\hline 1 & 0.2 & $\begin{array}{ll}1 & 0.2\end{array}$ & 1 & 0.2 \\
\hline 0.2 & 1 & 0.21 & 0.2 & 1 \\
\hline 1 & 0.6 & 10.6 & 1 & 0.6 \\
\hline 0.6 & 1 & 0.61 & 0.6 & 1 \\
\hline
\end{tabular}

larity between plant communities or classes of plant communities (vegetation types). From the table it is clear that if we consider that alpha diversity is the plant individual based diversity and beta diversity is the plant community based diversity, the "mathematics" for calculating both is absolutely the same.

\section{Simple examples with small artificial data}

In order to show how much a diversity based on $K \delta$ can change with respect $K$ and what could be the effect of considering similarity between the classes when we calculate $\delta$, I give some simple examples with three crispy similarity matrices given in Table 2 . All are derived by six units $(Q=$ 6 ) grouped into different ways in two classes $(K=2)$. B1, B2 and $\mathrm{B} 3$ are similarity matrices in which the 6 units belonging to 2 classes. The diversity vectors $(\mathrm{X})$, are respectively $\mathrm{B} 1=$ $(3,3), \mathrm{B} 2(4,2)$ and $\mathrm{B} 3(5,1)$, the corresponding $\mathrm{P}$ vectors are $\mathrm{B} 1(0.5,0.5), \mathrm{B} 2(0.67,0.33), \mathrm{B} 3(0.83,0.27)$.

The average dissimilarities according the Gini-Simpson index are: 0.5 in case of matrix B1 $(1-(18 / 36)) ; 0.44$ in case of matrix B2 $(1-(20 / 36)) ; 0.28$ in case of matrix B3 (1 - 
Table 4. Results of calculating diversity by formula 1) by using $\delta$ calculated in different ways for the similarity matrices and diversity vectors in Table 2. Legend to symbols: $\mathrm{s}=$ similarity; $\lambda=$ eigenvalues of similarity matrices; $\delta(\mathrm{E} \lambda)=$ evenness of the eigenvalues of similarity matrices; $\mathrm{P}=$ proportions of components of the vectors; $\mathrm{H}=$ Shannon entropy of the vectors; $\delta(\mathrm{EH})=$ eveness of the Shannon' $\mathrm{s}$ index $; \mathrm{G}=$ Gini-Simpson index of the vectors; $\delta(\mathrm{EG})=$ evenness of the Gini-Simpson index; $\Delta=$ Rao's index of dissimilarity matrices (complement to matrices in Table 2); $\delta(\mathrm{E} \Delta)=$ evenness of the Rao index; $\mathrm{H} \Delta=$ Ricotta and Szeidl' entropy index); $\delta(\mathrm{EH} \Delta)=$ evenness of the Ricotta and Szeidl' index; $\mathrm{K} \delta \mathrm{E}(\lambda)=\mathrm{D} 1 ; \mathrm{K} \delta(\mathrm{EH})=\mathrm{D} 2 ; \mathrm{K} \delta(\mathrm{EG})=\mathrm{D} 3 ; \mathrm{K} \delta(\mathrm{E} \Delta)=\mathrm{D} \Delta 1 ; \mathrm{K} \delta(\mathrm{EH} \Delta)=\mathrm{D} \Delta 2 ; \rho=\operatorname{loss}$ of diversity in \% (formula 6); D1, D2 and D3 are diversity measures calculated according to formula 1) without considering the dissimilarity matrices, while $\mathrm{D} \Delta 1$ and $\mathrm{D} \Delta 2$ are diversity measures calculated by formula 1) considering the dissimilarity matrices.

\begin{tabular}{|c|c|c|c|c|c|c|c|c|c|}
\hline & 1 & 2 & 3 & 4 & 5 & 6 & 7 & 8 & 9 \\
\hline $\mathrm{S}$ & 0.05 & 0.2 & 0.6 & 0.05 & 0.2 & 0.6 & 0.05 & 0.2 & 0.6 \\
\hline$\lambda$ & $(1.05,0.95)$ & $(1.2, .8)$ & $(1.6, .4)$ & $(1.05,0.95)$ & $(1.2,0.8)$ & $(1.6,0.4)$ & $(1.05,0.95)$ & $(1.2, .8)$ & $(1.6,0.4)$ \\
\hline$\delta(\mathrm{E} \lambda)$ & 0.998 & 0.97 & 0.72 & 0.998 & 0.97 & 0.72 & 0.998 & 0.97 & 0.72 \\
\hline $\mathrm{K} \delta(\mathrm{E} \lambda)$ & 1.996 & 1.94 & 1.44 & 1.996 & 1.94 & 1.44 & 1.996 & 1.94 & 1.44 \\
\hline$\rho(\delta(E \lambda)) \%$ & 0.2 & 3 & 28 & 0.2 & 3 & 28 & 0.2 & 3 & 28 \\
\hline $\mathrm{P}$ & $(0.5,0.5)$ & $(0.5,0.5)$ & $(0.5,0.5)$ & $(0.67,0.33)$ & $(0.67,0.33)$ & $(0.67,0.33)$ & $(0.83,0.17)$ & $(0.83, .17)$ & $(0.83,0.17)$ \\
\hline $\mathrm{H}$ & 0.69 & 0.69 & 0.69 & 0.63 & 0.63 & 0.63 & 0.46 & 0.46 & 0.46 \\
\hline$\delta(\mathrm{EH})$ & 1 & 1 & 1 & 0.92 & 0.92 & 0.92 & 0.65 & 0.65 & 0.65 \\
\hline $\mathrm{K} \delta(\mathrm{EH})$ & 2 & 2 & 2 & 1.84 & 1.84 & 1.84 & 1.3 & 1.3 & 1.3 \\
\hline$\rho(\delta(\mathrm{EH})) \%$ & 0 & 0 & 0 & 8 & 8 & 8 & 35 & 35 & 35 \\
\hline G & 0.5 & 0.5 & 0.5 & 0.44 & 0.44 & 0.44 & 0.28 & 0.28 & 0.28 \\
\hline$\delta(\mathrm{EG})$ & 1 & 1 & 1 & 0.88 & 0.88 & 0.88 & 0.56 & 0.56 & 0.56 \\
\hline $\mathrm{K} \delta(\mathrm{EG})$ & 2 & 2 & 2 & 1.76 & 1.76 & 1.76 & 1.12 & 1.12 & 1.12 \\
\hline$\rho(\delta(E G)) \%$ & 0 & 0 & 0 & 12 & 12 & 12 & 44 & 44 & 44 \\
\hline $\mathrm{RD}$ & 0.47 & 0.4 & 0.2 & 0.42 & 0.35 & 0.18 & 0.27 & 0.23 & 0.11 \\
\hline$\delta(E \Delta)$ & 0.94 & 0.8 & 0.4 & 0.84 & 0.7 & 0.36 & 0.54 & 0.46 & 0.22 \\
\hline $\mathrm{K} \delta(\mathrm{E} \Delta)$ & 1.88 & 1.6 & 0.8 & 1.68 & 1.4 & 0.72 & 1.08 & 0.92 & 0.44 \\
\hline$\rho(\delta(\mathrm{E} \Delta)) \%$ & 6 & 20 & 60 & 16 & 30 & 0.64 & 46 & 54 & 78 \\
\hline $\mathrm{H} \Delta$ & 0.64 & 0.51 & 0.22 & 0.59 & 0.46 & 0.2 & 0.41 & 0.31 & 0.13 \\
\hline$\delta(\mathrm{EH} \Delta)$ & 0.93 & 0.74 & 0.32 & 0.85 & 0.67 & 0.29 & 0.59 & 0.45 & 0.19 \\
\hline $\mathrm{K} \delta(\mathrm{EH} \Delta)$ & 1.86 & 1.48 & 0.64 & 1.7 & 1.34 & 0.58 & 1.18 & 0.9 & 0.38 \\
\hline$\rho(\delta(E H \Delta)) \%$ & 7 & 26 & 68 & 15 & 33 & 71 & 41 & 55 & 81 \\
\hline
\end{tabular}

(26/36)). To get $\delta$, we have to make relative these values to the maximal dissimilarity: the Gini-Simpson should be divided by its maximum value $(1-1 / K)$ i.e., 0.5 . So in case of $\mathrm{B} 1$ it is 1 , in case of $\mathrm{B} 2$ it is 0.88 , and in case of $\mathrm{B} 3$ it is 0.56 . Consequently, the diversity according to formula $K \delta$ will be for $\mathrm{B} 1=2 \times 1=2$, for $\mathrm{B} 2=2 \times 0.88=1.76$, for $\mathrm{B} 3=2 \times 0.56$ $=1.12$. If we use the Shannon formula, $\delta$ is calculated as the ratio between $H$ and $H_{\max }$. In this case the diversity of $\mathrm{B} 1=2$ $\times 1=2$, of $\mathrm{B} 2=2 \times 0.92=1.84$, and of $\mathrm{B} 3=2 \times 0.65=1.30$.

In case we want to calculate the fuzzy diversity the data are given by the similarity matrices $\mathbf{S}$ between classes and by the vectors $\mathrm{P}$ of the proportions of the classes. In Table 3 , there are 9 matrices of similarity corresponding to the three above diversity vectors $(\mathrm{B} 1(0.5,0.5), \mathrm{B} 2(0.67,0.33), \mathrm{B} 3(0.83$, $0.17)$ ), with three different levels of between class similarity $(0.05,0.2$ and 0.60$)$.

If we do not consider the weight of the classes (namely the $\mathrm{P}$ vectors) the $\delta$ due to dissimilarity is 0.95 , for the level of similarity equal to 0.05 , to 0.80 for the level equal to 0.20 , and 0.40 to the level equal to 0.60 . It means that the diversity will be $2 \times 0.95=1.90,2 \times .80=1.60$ and to $2 \times .40=0.80$. If we consider $\delta$ as the evenness of the eigenvalues of the similarity matrices (Table 4), it is 0.998 for the level of $0.05,0.97$ for the level of 0.2 and 0.72 for the level 0.6. Therefore, the diversity according to $K \delta$ will be respectively $1.996,1.94$ and 1.44 , a little higher than in the previous case. Table 4 gives values for several diversity statistics related to the matrices and the diversity vectors in Table 3. Diversity and evenness are calculated for the data in Table 3, according to the formula of Rao (1982), i.e the weighted average of the dissimilarity matrix, and the formula of Ricotta and Szeidl (2006), i.e., the weighted entropy of the proportions by the similarity between the classes. It is clear from the values of $\delta$ in Table 4 that similar values can be obtained by different combinations of similarity and equitability.

If we consider just the diversity numbers calculated by $\mathrm{K} \delta$ for $\delta$ calculated as the evenness of the formula of Ricotta and Szeidl (2006), keeping fixed the equitability to 1, the dec- 
rement of diversity, when from a similarity between classes of 0.05 we go to a similarity of 0.60 , is passing from $7 \%$ to $68 \%$, while for an equitability of 0.92 it is passing from 5 to $71 \%$ and for an equitability of 0.65 we go to a decrement from $41 \%$ to $81 \%$. If we keep fixed the similarity at 0.05 passing from an equitability of 1 to an equitability of $0.65, K \delta$ loses from $7 \%$ to $41 \%$; for a similarity level of 0.20 the loss by decrement of equitability is from $26 \%$ to $55 \%$ and finally for the similarity at 0.60 the loss from the equitability of 1 to the equitability at 0.56 is from $68 \%$ to $81 \%$. We can conclude that, as we can expect, the decrement of evenness of the proportions at lower levels of similarity (e.g., 0.05) influence less the diversity values, while at lower levels of evenness the increment of similarity produces a considerable lowering of the diversity.

\section{Conclusions}

This paper is a discussion from its beginning so a "chapter discussion" would not be necessary. However, I would like to conclude by seven simple considerations concerning the importance of studying and measuring diversity of vegetation systems by $K, \delta$ and $\rho$ :

1) In the literature, there is a heavy theoretical debate on diversity (biodiversity) especially in relation to the stability of ecosystems (see McCann 2000, Tilman et al. 2014). The theoretical debate in vegetation science is focused on the plant community concept and involves mainly the plant individual based diversity (alpha diversity of Whittaker). However, the research and discussions are also related to phylogenetic similarity between plant communities and to explain different kinds of diversity in terms of functional traits of the different species with the hope to find general assembly rules and clear explanations about environmental filtering (Wilson 1994, Kraft and Ackerly 2014). These are keywords for many papers on diversity, which are addressed to find explanations for vegetation variation along gradients or in time. Certainly if we consider phylogenetic trees (Podani 2007, Pavoine 2016), the matrices $\mathbf{S}$ that we can get from them could be useful to infer on mechanisms of coevolution (Levin 1983a,b, Wilson 2011) and or convergent evolution (MacArthur and Levins 1967, Orlóci et al. 1986). Of great interest in analyzing mechanisms that "produce" diversity are the results of Mazzoleni et al. (2007, 2010 and 2015). According to these papers, I would like to emphasize that environmental homogeneity would "produce" plant individual based diversity (alpha diversity of Whittaker 1960, 1972), while environmental heterogeneity would "produce" plant community based diversity (beta diversity of Feoli et al. 1988).

2) The number of classes $K$ is the basic measure, both for the plant individual-based diversity and for the plant communitybased diversity. Once $K$ has been defined, it may be corrected, if necessary, by an index $\delta$, calculated by one of many criteria that would measure the similarity within the system under study using intrinsic or extrinsic characters and by including or not the proportion of the classes in terms of their importance. Diversity profiles according to Rényi (1961), Hill (1973) and Leinster and Cobbold (2012) generalizing the en- tropy can be used to evaluate the effects of "weighting" the importance of the classes in different ways.

3) An index $\rho$ can be calculated to measure how much the diversity given by $K$ would be reduced by $\delta$. This may be useful to understand relationships between different sets of characters intrinsic and extrinsic.

4) $K, \delta$ and $\rho$ are useful tools to investigate vegetation diversity patterns related to phylogeny, functionality and structure of vegetation. For example if for a set A of $K$ classes of objects, $\delta$ is calculated considering one set of characters (features F1) that, for instance, represent the mutual phylogenetic position of the $K$ classes (or $\mathbf{S}$ is a topological distance matrix of the evolutionary tree, see Podani 2007, Ricotta et al. 2018 and references therein) and the $K$ classes are described also by a set (features F2) that may represent their similarity in terms of structure, then if $\rho_{1}$, corresponding to $F 1$ is larger than $\rho_{2}$, corresponding to $F 2$, it would mean that there is a structural divergence, while $\rho_{1}<\rho_{2}$ would represent a structural convergence (obviously for the characters we have chosen).

5) The concept of diversity has aroused too many discussions both for its meaning and its measurement which, at least for me, were not much necessary after the generalizations of Rényi (1961) and Hill (1973). Diversity, notwithstanding Hurlbert (1971), is a clear concept that relies on classification and similarity between the classes obtained by identification or classification processes after data collection. In vegetation science, diversity may be based on plant individuals (that if we like we can call alpha diversity) or on plant community (that if we like we can call beta diversity) and may be fuzzy or crisp, that's all. The term beta diversity should be used only to indicate the number of classes of plant community of a vegetation system (corrected by $\delta$ if necessary) and should be avoided to indicate similarity-dissimilarity (e.g., Anderson et al. 2011).

6) Thanks to available mathematical tools and in particular to eigenanalysis of similarity matrices, by which we can define many levels of significant $K$ and we can define $\delta$ accordingly, we can say that it would be better to be worried about why we are willing to measure diversity rather than about the method or the formula we have to use.

7) The "infinite" possibilities of using diversity measures, including those based on $K$ and $\delta$, and the new upcoming views and ideas such those related to "quantum ecology" (Orlóci 2013, 2014, 2015 a,b), push me to close this paper to recall an expression from Dale (1988): "the choice is yours" (i.e., ours).

Acknowledgements. I thank P. Ganis, J. Podani, L. Orlóci, C. Ricotta and O. Wildi for having read the paper and for their comments. However, only I am responsible for possible errors. Many thanks are also addressed to the organizers of the $1^{\text {st }}$ International Conference on Community Ecology (Sept 28-29, 2017, Budapest) for financial support offered to me to participate to the conference to present this paper.

\section{References}

Allen, T.F.H. and T.B. Starr. 1982. Hierarchy: Perspectives for Ecological Complexity. University of Chicago Press, Chicago. 
Anderson, M.J., T.O. Crist, J.M. Chase, M. Vellend, B.D. Inouye, A.L. Freestone, N.J. Sanders, H.V. Cornell, L.S. Comita, K.F. Davies, S.P. Harrison, N.J.B. Kraft, J.C. Stegen and N.G. Swenson. 2011. Navigating the multiple meanings of $\beta$ diversity: a roadmap for the practicing ecologist. Ecol. Lett. 14:19-28.

Avena, G.C., Blasi, E. Feoli and A. Scoppola. 1981. Measurement of the predictive value of species lists for species cover in phytosociological samples. Vegetatio 45:77-84.

Biondi, E., E. Feoli and V. Zuccarello 2004. Modelling environmental responses of plant associations: a review of some critical concepts in vegetation study. Crit. Rev. Plant. Sci. 23:149-156.

Biondini, M.E., P.W. Mielke Jr. and E.F. Redente. 1991. Permutation techniques based on Euclidean analysis spaces: A new and powerful statistic method for ecological research. In: E. Feoli and L. Orlóci (eds), Computer assisted vegetation analysis. Kluwer, Boston. pp. 221-240

Botta-Dukát, Z. 2005. Rao's quadratic entropy as a measure of functional diversity based on multiple traits. J. Veg. Sci. 16:533-540.

Braun-Blanquet, J. 1964. Pflanzensoziologie. Gründzuge der Vegetationskunde. 3th ed. Springer, Wien.

Burba, N., E. Feoli, M. Malaroda and V. Zuccarello. 1992. Un sistema informativo per la vegetazione. Software per l'archiviazione della vegetazione italiana e per l'elaborazione di tabelle. Manuale di utilizzo dei programmi. GEAD-EQ n.11. Università degli Studi di Trieste.

Chiarucci, A., G. Bacaro, A. Vanini and D. Rocchini. 2008 Quantifying species richness at multiple spatial scales in a Natura 2000 network. Community Ecol. 9:185-192.

Chiarucci, A., G. Bacaro, G. Filibeck, S. Landi, S. Maccherini and A. Scoppola 2012. Scale dependence of plant species richness in a network of protected areas. Biodivers. Conserv. 21:503-516.

Dale, M.B. 1988. Knowing when to stop: cluster concept-concept cluster. Coenoses 1:11-31.

Dale, M.B. 1994. Do ecological communities exist? J. Veg. Sci. 5:285-286

Dale, M.B., E. Feoli and P. Ganis. 1989. Incorporation of information from the taxonomic hierarchy in comparing vegetation types. Taxon 38:216-227.

Darwin, C. 1859. On the Origin of Species by Means of Natural Selection, or the Preservation of Favoured Races in the Struggle for Life (1st ed.). John Murray, London.

de Bello, F., J. Lepš, S. Lavorel and M. Moretti 2007. Importance of species abundance for assessment of trait composition: an example based on pollinator communities. Community Ecol. $8: 163-170$

De Cáceres, M., M. Chytrý, E. Agrillo, F. Attorre, Z. Botta-Dukát, J. Capelo, B. Czúcz, J. Dengler, J. Ewald, D. Faber-Langendoen, E. Feoli, S.B. Franklin, R. Gavilán, F. Gillet, F. Jansen, B. Jiménez-Alfaro, P. Krestov, F. Landucci, A. Lengyel, J. Loidi, L. Mucina, R.K. Peet, D.W. Roberts, J. Roleček, J.H.J. Schaminée, S. Schmidtlein, J.P. Theurillat, L. Tichý, D.A. Walker, O. Wildi, W. Willner and S.K. Wiser. 2015. A comparative framework for broad-scale plot-based vegetation classification. Appl. Veg. Sci. 18:543-560.

Duarte, L.D.S., V.J. Debastiani, A.V. L. Freitas and V. Pillar. 2016 Dissecting phylogenetic fuzzy weighting: theory and application in metacommunity phylogenetic. Meth. Ecol. Evol. 7:937-946.

Feoli, E. 1977. On the resolving power of principal component analysis in plant community ordination. Vegetatio 33:119-125.

Feoli, E. 1983. Predictive use of classification and ordination methods in plant community ecology. A summary with examples. In: C. Ferrari, S. Gentile, S. Pignatti and E. Poli Marchese, Le comunità vegetali come indicatori ambientali. Regione Emila Romagna (Assessorato Ambiente) e Società Italiana di Fitosociologia. pp. $83-108$.

Feoli, E. 1984a. Some aspects of classification and ordination of vegetation data in perspective. Studia Geobot. 4:7-21.

Feoli, E. 1984b. Is there any correlation between anatomical spaces of vegetation and its sampling space? Giorn. Bot. Ital. 118:98-100.

Feoli, E. 2010. Heath species and heathlands of Italy: an analysis of their relationships under the perspective of climate change based on the description of habitats used for the project "Carta della Natura" (Italian Map of Nature). Ecol. Questions 12:161-170.

Feoli, E. 2012. Diversity patterns of vegetation systems from the perspective of similarity theory. Plant Biosyst. 146:797-804.

Feoli, E and P. Ganis. 1985. Comparison of floristic vegetation types by multiway contingency tables. Abstr. Bot. 9:1-15.

Feoli, E. and M. Lagonegro. 1982. Syntaxonomical analysis of beech woods in the Apennines (Italy) using the program package IAHOPA. Vegetatio 50:129-173.

Feoli, E. and D. Lausi. 1980. Hierarchical levels in syntaxonomy based on information functions. Vegetatio 42:113-115.

Feoli, E. and L. Orlóci. 1979. Analysis of concentration and detection of underlying factors in structured tables. Vegetatio 40:49-54.

Feoli, E. and L. Orlóci. 1991. The properties and interpretation of observations in vegetation study. In: E. Feoli, L. Orlóci (eds), Computer Assisted Vegetation Analysis. Kluwer, Boston. pp. 3-13.

Feoli, E. and L. Orlóci. 2011. Can similarity theory contribute to the development of a general theory of the plant community? Community Ecol. 12:135-141.

Feoli, E and M. Scimone. 1984a. Hierarchical diversity: an application to broad-leaved woods of the Apennines. Giorn. Bot. Ital. 118:1-15.

Feoli, E. and M. Scimone. 1984b. A quantitative view of textural analysis of vegetation and examples of application of some methods. Arch. Bot. Biogeogr. Ital. 60:73-94.

Feoli, E and V. Zuccarello. 1986. Ordination based on classification: yet another solution?! Abstr. Bot. 10:203-219.

Feoli, E. and V. Zuccarello. 2013. Fuzzy sets and eigenanalysis in community study: classification and ordination are two faces of the same coin. Community Ecol. 14:164-171.

Feoli, E., G. Ferro and P. Ganis. 2006. Validation of phytosociological classifications based on a fuzzy set approach. Community Ecol. 7:98-117.

Feoli, E., P. Ganis and C. Ricotta. 2013. Measuring diversity of environmental systems. In: J.J. Ibanez and J. Bockeim (eds.), Pedodiversity. CRC Press Taylor and Francis. pp. 29-58.

Feoli, E., P. Ganis and Zerihun Woldu. 1988. Community niche, an effective concept to measure diversity of gradients and hyperspaces. Coenoses 3:31-34.

Feoli, E., M. Lagonegro and L. Orlóci. 1984. Information Analysis of Vegetation Data. Dr. W. Junk Publishers, The Hague.

Feoli, E, L. Gallizia Vuerich, P. Ganis and Zerihun Woldu. 2009 A classificatory approach integrating fuzzy set theory and permutation techniques for land cover analysis: a case study on a degrading area of the Rift Valley (Ethiopia). Community Ecol. 10:53-64.

Feoli, E., P. Ganis, G. Oriolo and A. Patrono. 1992. Modelli per il calcolo della diversità e loro applicabilità nella valutazione $\mathrm{di}$ impatto ambientale. S.IT.E. Atti 14:29-34

Ferrari, C., S. Gentile, S. Pignatti and E. Poli Marchese (eds.). 1983 Le comunità vegetali come indicatori ambientali. Regione 
Emila Romagna (Assessorato Ambiente) e Società Italiana di Fitosociologia, Bologna.

Gorelick, R. 2011. Commentary: Do we have a consistent terminology for species diversity? The fallacy of true diversity. Oecologia 167:885-888.

Hill, M.O. 1973. Diversity and evenness: a unifying notation and its consequences. Ecology 54:427-432.

Hui, C. 2008. On species-area and species accumulation curves: a comment on Chong and Stohlgren's index. Ecol. Indic. 8:327329.

Hui, C. and M.A. McGeoch. 2008. Does the self-similar species distribution model lead to unrealistic predictions? Ecology 89:2946-2952.

Hui, C. and M.A. McGeoch. 2014. Zeta diversity as a concept and metric that unifies incidence-based biodiversity patterns. Am. Nat. 184:684-694.

Hurlbert, S.H. 1971. The nonconcept of species diversity: a critique and alternative parameters. Ecology 52:577-586.

Jost, L. 2007. Partitioning diversity into independent alpha and beta components. Ecology 88:2427-2439.

Jost, L. 2010. The relation between evenness and diversity. Diversity 2:207-232

Juhász-Nagy, P. 1993. Notes on compositional diversity. Hydrobiologia 249:173-182.

Jurasinski, G. and M. Koch. 2011. Commentary: do we have a consistent terminology for species diversity? We are on the way. Oecologia 167:893-902.

Keddy, P. 1993. Do ecological communities exist? A reply to Bastow Wilson. J. Veg. Sci. 4:135-136.

Kizekova, M., E. Feoli, G. Parente and R. Kanianska. 2017. Analysis of the effects of mineral fertilization on species diversity and yield of permanent grasslands: revisited data to mediate economic and environmental needs. Community Ecol. 18:295-304.

Kraft, N.J.B and D.D. Ackerly. 2014. Assembly of plant communities. In: R.K. Monson (ed.), Ecology and the Environment, The Plant Sciences 8. Springer, New York.

Leinster, T. and C.A. Cobbold. 2012. Measuring diversity: the importance of species similarity. Ecology 93:477-489.

Levin, S.A. 1983a. Coevolution. In: H.I. Freedman and C. Strobeck (eds.), Population Biology. Lecture notes in Biomathematics 52:328-334.

Levin, S.A. 1983b. Some approaches to the modelling of coevolutionary interactions. In: M. Nitecki (ed.), Coevolution. University of Chicago Press. pp. 21-65

MacArthur, R. and R. Levins. 1967. The limiting similarity, convergence, and divergence of coexisting species. Am. Nat. 101(921): $377-385$

Magurran, A.E. 1988. Ecological Diversity and its Measurement. Croom Helm, London/Sydney.

Magurran, A.E. 2004. Measuring Biological Diversity. Blackwell, Oxford.

Maignan, C., G. Ottaviano, Pinelli, D., Rullani, F. 2003. Bioecological diversity vs. socio-economic diversity: A comparison of existing measures. Working Papers Fondazione Eni Enrico Mattei. 13.

Margalef, R. 1958. Information theory in ecology. Gen. Syst. 3:3671.

Mason, N.V.H., D. Mouillot, W.G. Lee and J.B. Wilson. 2005. Functional richness, functional evenness and functional divergence: the primary components of functional diversity. Oikos 111:112-118.
Mazzoleni, S., G. Bonanomi, F. Giannino, G. Incerti, S.C. Dekker and M. Rietkerk. 2010. Modelling the effects of litter decomposition on tree diversity patterns. Ecol Model. 221:2784-92.

Mazzoleni, S., G. Bonanomi, F. Giannino, M.G. Rietkerk, S.C. Dekker and F. Zucconi. 2007. Is plant biodiversity driven by decomposition processes? An emerging new theory on plant diversity. Community Ecol. 8:103-109.

Mazzoleni, S., F. Carteni, G. Bonanomi, M. Senatore, P. Termolino, F. Giannino, G. Incerti, M. Rietkerk, V. Lanzotti and M.L. Chiusano. 2015. Inhibitory effects of extracellular self-DNA: a general biological process? New Phytol. 206:127-32.

McCann, K.S. 2000. The diversity-stability debate. Nature 405:228233.

Moreno, C.E. and P. Rodríguez. 2011. Commentary: Do we have a consistent terminology for species diversity? Back to basics and toward a unifying framework. Oecologia 167:889-892.

Mueller-Dombois, D. and H. Ellenberg. 1974. Aims and Methods of Vegetation Ecology. John Wiley \& Sons, New York.

Newman, E.I. (ed.) 1982. The Plant Community as a Working Mechanism. Blackwell Scientific Publications, Oxford.

Orlóci, L. 1972. On objective functions of phytosociological resemblance. Am. Midl. Nat. 88:28-55.

Orlóci, L. 1978. Multivariate Analysis in Vegetation Research. 2nd ed. Dr. Junk, The Hague.

Orlóci, L. 2013. Quantum Analysis of Primary Succession. The Energy Structure of a Vegetation Chronosere in Hawai'i Volcanoes National Park. SCADA Publishing, Canada. Online Edition: https://createspace.com/4452597

Orlóci, L. 2014. Quantum Ecology. Energy Structure and its Analysis. SCADA Publishing, Canada. Online Edition: https:// createspace.com/4406077

Orlóci, L. 2015a. Diversity Analysis, Holistic Energetics, and Statistics. The Resonator Complex Model of the Vegetation Stand. SCADA Publishing, Canada. Online Edition: https://createspace.com/5783923

Orlóci, L. 2015b. Energy-based Vegetation Mapping. A Case Study in Statistical Quantum Ecology. SCADA Publishing, Canada. Online Edition: https://createspace.com/5495773.

Orlóci, L. and M. Orlóci. 1985. Comparison of communities without the use of species: model and examples. Ann. Bot. 43:275-285.

Orlóci, L., E. Feoli, D. Lausi and P.L. Nimis. 1986. Estimation of character structure convergence (divergence) in plant communities: a nested hierarchical model. Coenoses 1:11-20.

Palmer, M.W. and P.S. White. 1994. On the existence of ecological communities. J. Veg. Sci. 5: 279-282.

Patil, G.P. and C. Taillie. 1976. Ecological diversity: concepts, indices and applications. In: Proceedings of the 9th Int. Biometric conference. The Biometric Society. 2:383-411.

Pavoine, S. 2016. A guide through a family of phylogenetic dissimilarity measures among sites. Oikos 125:1719-1732.

Pavoine, S., M.S. Love and M.B. Bonsall. 2009. Hierarchical partitioning of evolutionary and ecological patterns in the organization of phylogenetically-structured species assemblages: application to rockfish (genus: Sebastes) in the Southern California Bight. Ecol. Lett. 12:898-908.

Pavoine, S., E. Marcon and C. Ricotta. 2016. 'Equivalent numbers' for species, phylogenetic or functional diversity in a nested hierarchy of multiple scales. Meth. Ecol. Evol. 7:1152-1163.

Pavoine, S., S. Ollier and D. Pontier. 2005. Measuring diversity from dissimilarities with Rao's quadratic entropy: Are any dissimilarities suitable? Theor. Popul. Biol. 67:231-239. 
Pesarin, F. 2001. Multivariate Permutation Tests. With Applications in Biostatistics. John Wiley \& Sons, Chichester, Toronto.

Pielou, E.C. 1975. Ecological Diversity. Wiley, New York.

Pillar, V. 1999. How sharp are classifications? Ecology 80:25082516.

Pillar, V. and L. Orlóci 1993. Character-Based Community Analysis The Theory and an Application Program. SPB Academic Publishing bv, The Hague, The Netherlands.

Pillar, V. and L. Orlóci. 1996. On randomization testing in vegetation science: Multifactor comparisons of relevé groups. J. Veg. Sci. $7: 585-592$

Pillar, V. and L. Orlóci. 2004. Character-based community analysis: The theory and an application program. Available: http://ecoqua.ecologia.ufrgs.br

Pillar, V., L.D.S. Duarte, E.E. Sosinski and F. Joner. 2009. Discriminating trait-convergence and trait-divergence assembly patterns in ecological community gradients. J. Veg. Sci. 20:334348.

Podani, J. 2000. Introduction to the Exploration of Multivariate Biological Data. Backhuys Publishers, Leiden.

Podani, J. 2006. With a machete through the jungle: some thoughts on community diversity. Acta Biotheor. 54: 125-131.

Podani, J. 2007. Analisi ed esplorazione multivariate dei dati in Ecologia e Biologia. Liguori editore, Napoli.

Podani, J. and D. Schmera. 2011. A new conceptual and methodological framework for exploring and explaining pattern in presenceabsence data. Oikos 120:1625-1638.

Rao, C.R. 1982. Diversity and dissimilarity measurements: a unified approach. Theor. Popul. Biol. 21:24-43.

Rao, C.R. 2010. Quadratic entropy and analysis of diversity. Sankhyā: Ind. J. Stat. 72-A(1):70-80

Rényi, A. 1961. On measure of entropy and information. In: J. Neyman (ed.), The Proceedings of the 4th Berkeley Symposium on Mathematical Statistics and Probability. Univ. Calif. Press, Berkeley, CA. pp. 547-561.

Ricotta, C. 2003. On parametric evenness measures. J. Theor. Biol. 222:189-197.

Ricotta, C. 2004. A recipe for unconventional evenness measures. Acta Biotheor. 52:95-104.

Ricotta, C. 2017. Of beta diversity, variance, evenness, and dissimilarity. Ecol. Evol. 7:4835-4843.

Ricotta, C. and M. Anand. 2006. Spatial complexity of ecologica communities: Bridging the gap between probabilistic and nonprobabilistic uncertainty measures. Ecol. Model. 197:59-66.

Ricotta, C. and M. Marignani. 2007. Computing $\beta$-diversity with Rao's quadratic entropy: A change of perspective. Divers. Distrib.13:237-241.

Ricotta, C. and S. Pavoine. 2015. A multiple-site dissimilarity measure for species presence/absence data and its relationship with nestedness and turnover. Ecol. Indic. 54:203-206.

Ricotta, C. and L. Szeidl. 2006. Towards a unifying approach to diversity measures: bridging the gap between Shannon entropy and Rao's quadratic index. Theor. Popul. Biol. 70:237-243.

Ricotta, C. and L. Szeidl. 2009. Diversity partitioning of Rao's quadratic entropy. Theor. Popul. Biol. 76:299-302.

Ricotta, C,E. De Zuliani, A. Pacini and G.C. Avena. 2001. On the mutual relatedness of evenness measures. Community Ecol. 2:51-56.

Ricotta, C., G. Bacaro, M. Caccianiga, B.E.L. Cerabolini and M. Moretti. 2015. A classical measure of phylogenetic dissimilar- ity and its relationship with beta diversity. Basic Appl. Ecol. 16:10-18.

Ricotta, C., G. Bacaro, M. Caccianiga, B.E.L. Cerabolini and S. Pavoine. 2018. A new method for quantifying the phylogenetic redundancy of biological communities. Oecologia 186:339-346.

Ricotta, C., E. Ari, G. Bonanomi, F. Giannino, D. Heathfield, S. Mazzoleni and J. Podani. 2017. Spatial analysis of phylogenetic community structure: New version of a classical method. Community Ecol. 18:37-46.

Roberts, D.W. 1986. Ordination on the basis of fuzzy set theory. Vegetatio 66:123-131.

Schmera, D. and J. Podani. 2018. Through the jungle of methods quantifying multiple-site resemblance. Ecol. Inform. 44:1-6.

Tichý, L. 2002. JUICE, software for vegetation classification. J. Veg. Sci. 13:451-453.

Tichý, L. and J. Holt. 2006. JUICE, program for management, analysis and classification of ecological data. Masaryk University, Brno, CZ.

Tichý, L, M. Chytrý, M. Hájek, S.S. Talbot and Z. Botta-Dukát. 2010 OptimClass: using species-to-cluster fidelity to determine the optimal partition in classification of ecological communities. $J$. Veg. Sci. 21:287-299.

Tilman, D., F. Isbell, and J. Cowles. 2014. Biodiversity and ecosystem functioning. Annu. Rev. Ecol. Evol. Syst. 45:471-493.

Tuomisto, H. 2010a. A diversity of beta diversities: straightening up a concept gone awry. Part 1 . Defining beta diversity as a function of alpha and gamma diversity. Ecography 33:2-22.

Tuomisto, H. 2010b. A consistent terminology for quantifying species diversity? Yes, it does exist. Oecologia 4:853-860.

Tuomisto, H. 2011. Commentary: do we have a consistent terminology for species diversity? Yes, if we choose to use it. Oecologia 167:903-911.

van der Maarel, E. 1975. The Braun-Blanquet approach in perspective. Vegetatio 30:213-219.

van der Maarel, E. 1996. Pattern and process in plant community. Fifty years after A.S. Watt. J. Veg. Sci. 7:19-28.

van der Maarel, E. 2005. Vegetation ecology - an overview. In: E. van der Maarel (ed.) Vegetation Ecology. Blackwell, UK. pp. $1-51$.

Von Bertalanffy, L. 1968. General System Theory. George Braziller, New York.

Watt, A.S. 1947. Pattern and process in the plant community. J. Ecol. $35: 1-22$.

Whittaker, R.H. 1960. Vegetation of the Siskiyou Mountains, Oregon and California. Ecol. Monogr. 30:279-338.

Whittaker, R.H. 1972. Evolution and measurement of species diversity. Taxon 21:213-251.

Wildi, O. 2017. Data Analysis in Vegetation Ecology. 3rd ed. CABI, Wallingford, UK

Wilkinson, J.H. 1965. The Algebraic Eigenvalue Problem. Oxford University Press, London.

Wilson, J.B. 1991. Does vegetation science exist? J. Veg. Sci. 2:289290

Wilson, J.B. 1994. Who makes the assembly rules? J. Veg. Sci. 5:275-278

Wilson, J.B. 2011. The twelve theories of co-existence in plant communities: the doubtful, the important and the unexplored. J. Veg. Sci. 22:184-195. 
Wilson, J.B. 2012. Species presence/absence sometimes represents a plant community as well as species abundances do, or better. $J$. Veg. Sci. 23:1013-1023.

Wilson, J.B. and A. Chiarucci. 2000. Do plant communities exist? Evidence from scaling up local species-area relations to the regional level. J. Veg. Sci. 11(5):773-775.

Wilson, J.B., R.K. Peet and M.T. Sykes. 1995. What constitutes evidence of community structure? A reply to van der Maarel, Noest and Palmer. J. Veg. Sci. 6:753-758.

Zadeh, L.A. 1965. Fuzzy sets. Inform. Control 8:338-353.
Zadeh, L.A. 1978. Fuzzy sets as a basis for a theory of possibility. Fuzzy sets and systems 1:3-28.

Zhao, S.X. 1986. Discussion on fuzzy clustering. In: 8th Int. Conference on Pattern recognition. IEEE Press, New York. pp. 612-614.

Zimmerman, H. 1996. Fuzzy Set Theory and its Applications. 3rd ed. Kluwer, Dordrecht.

Received January 20, 2018

Revised May 15, 2018

Accepted June 15, 2018 